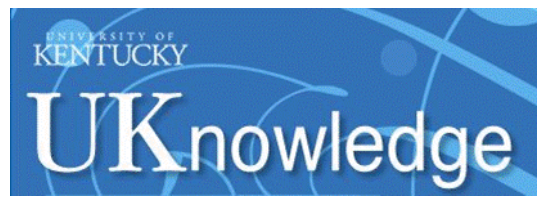

University of Kentucky

UKnowledge

Biosystems and Agricultural Engineering Faculty Publications

2016

\title{
Nozzle Sensor for In-System Chemical Concentration Monitoring
}

Joseph S. Dvorak

University of Kentucky, joe.dvorak@uky.edu

Timothy S. Stombaugh

University of Kentucky, tim.stombaugh@uky.edu

Yongbo Wan

University of Kentucky, yongbo.wan@uky.edu

Follow this and additional works at: https://uknowledge.uky.edu/bae_facpub

Part of the Bioresource and Agricultural Engineering Commons, and the Plant Sciences Commons Right click to open a feedback form in a new tab to let us know how this document benefits you.

\section{Repository Citation}

Dvorak, Joseph S.; Stombaugh, Timothy S.; and Wan, Yongbo, "Nozzle Sensor for In-System Chemical Concentration Monitoring" (2016). Biosystems and Agricultural Engineering Faculty Publications. 43. https://uknowledge.uky.edu/bae_facpub/43

This Article is brought to you for free and open access by the Biosystems and Agricultural Engineering at UKnowledge. It has been accepted for inclusion in Biosystems and Agricultural Engineering Faculty Publications by an authorized administrator of UKnowledge. For more information, please contact UKnowledge@lsv.uky.edu. 
Nozzle Sensor for In-System Chemical Concentration Monitoring

Digital Object Identifier (DOI)

https://doi.org/10.13031/trans.59.11473

Notes/Citation Information

Published in Transactions of the ASABE, v. 59, issue 5, p. 1089-1099.

๑) 2016 American Society of Agricultural and Biological Engineers

The copyright holder has granted the permission for posting the article here. 


\title{
NOZZLE SENSOR FOR IN-SYSTEM CHEMICAL CONCENTRATION MONITORING
}

\author{
J. S. Dvorak, T. S. Stombaugh, Y. Wan
}

\begin{abstract}
Chemical concentration is a vital parameter for determining appropriate chemical application. This study describes the design and testing of a sensor that attempted to monitor concentration of chemicals upstream from each nozzle body. The sensor is based on an LED and photodiode pair. Its ability to detect chemical concentration within the main carrier was tested with a 2,4-D formulation, a glyphosate formulation, and a powdered Acid Blue 9 dye. The liquid herbicide formulations of glyphosate and 2,4-D were tested across common application concentrations of $0 \%$ to $12.5 \%$ by volume. The powdered dye produced a much stronger effect on the sensor and was only tested at the much lower concentrations of 0 to $50 \mathrm{mg} \mathrm{L}^{-1}$. Further tests were conducted in which the dye was mixed with the herbicide formulation before the combined solution was added to the carrier. While this enabled establishment of pre-determined sensor outputs based on given concentrations of the pre-mixed solution, the sensor may have been responding to the predominance of a dye mixed with a herbicide formulation and not directly to the concentration of the herbicide. While the sensor did not appreciably respond to the concentration of the glyphosate formulation, it did respond in a consistent manner to the 2,4-D formulation and the dye. The sensor's response to the concentration of these chemicals was a rational (1/x type) relationship, and the $R^{2}$ values for the rational models describing these relationships were greater than 0.99. With the mixed dye and herbicide formulation, the effects of the dye and the 2,4-D formulation combined independently, and the total sensor output was a multiplication of the percent effect of each alone. The test with the pre-mixed dye and 2,4-D formulation produced the expected 1 V output at a $12.5 \%$ by volume concentration of the 2,4-D formulation, proving that dye can be added to a herbicide to produce a desired response from the sensor. Overall, the sensor's response was remarkably stable, with a maximum standard deviation of $42.2 \mathrm{mg} \mathrm{L} \mathrm{L}^{-1}$ of 2,4-D active ingredient for samples taken at a constant chemical concentration. These tests confirmed that the sensor could respond to chemical formulations and dye in a consistent and predictable manner. However, use of the sensor for herbicide monitoring will require sensor calibration for each combination of herbicide and dye mixture, as the light transmittance properties of the tested mixtures were not quantified and the light transmittance properties of formulations and dyes can be arbitrarily changed by manufacturers.
\end{abstract}

Keywords. Concentration, Optical, Pesticide, Sensor, Sprayers.

$\mathrm{T}$ The ultimate goal of any spray application is to apply the exact desired amount of chemical at every location in a field. The amount of chemical application is determined by the flow rate of the spray mixture and the concentration of the chemical within that mixture. Within widely used tank mix systems, the concentration should be constant, so flow control is the primary method of controlling application rates. Flow rate sensors to monitor flow at the nozzle level are commercially available (Sentry 6140 Tip Flow Monitor, TeeJet, Glendale Heights, Ill., or Flow View Ball Flow Indicators, Wilger, Lexington,

Submitted for review in August 2015 as manuscript number MS 11473; approved for publication by the Machinery Systems Community of ASABE in May 2016.

Publication No. 17-05-084 of the Kentucky Agricultural Experiment Station, published with the approval of the Director.

The authors are Joseph Dvorak, ASABE Member, Assistant Professor, Timothy Stombaugh, ASABE Member, Professor, and Yongbo Wan, ASABE Member, Post-Doctoral Scholar, Department of Biosystems and Agricultural Engineering, University of Kentucky, Lexington, Kentucky. Corresponding author: Joseph S. Dvorak, Department of Biosystems and Agricultural Engineering, University of Kentucky, 128 C.E. Barnhart Building, Lexington, KY 40546-0276; phone: 859-257-5658; e-mail: joe.dvorak@uky.edu.
Tenn.), and many studies have focused on varying the flow rate of the mixed spray solution through pressure control, PWM control of nozzles, or other advanced techniques (Ayers et al., 1990; Bode and Bretthauer, 2007; Liu et al., 2014; Luck et al., 2011; Needham et al., 2012; Porter et al., 2013; Sharda et al., 2010a, 2010b; Womac and Bui, 2002). The other half of appropriate chemical application (chemical concentration) is more important within direct injection systems, where it can be varied by the control system.

Determination of chemical concentration in direct injection systems has generally focused on sensing changes either in optical properties or electrical conductivity. In an early direct injection study, Tompkins et al. (1990) determined concentration using a potassium bromide solution and analyzing changes in conductivity. Gillis et al. (2003) analyzed conductivity using a $20,000 \mathrm{ppm} \mathrm{NaCl}$ salt solution to determine chemical application concentration for a target-activated injection system. In further work by the group (Crowe et al., 2005), the characteristics of the conductivity sensor were described, and it was found to be highly accurate and capable of detecting high-frequency fluctuations in the concentration of $\mathrm{NaCl}$ salt solutions. This idea was taken even further by Mercaldi et al. (2015), who developed a sensor 
using this principle that could be embedded within a standard nozzle body.

Other researchers have determined the concentration or presence of chemicals through optical properties. Sudduth et al. (1995) used potassium permanganate to study concentration consistency in direct injection systems. In a series of articles on direct injection, Zhu et al. (1998a, 1998b, 1998c) used fluorescence tracers (UVITEX OB and Acid Yellow 7 dye) to evaluate lag time, solution uniformity, and spray pattern uniformity and to investigate factors that contribute to lag time. Sumner et al. (2000) used fluorescent dye (Rhodamine WT) and string collectors placed along the sprayer path to evaluate lag time as well. Non-fluorescent blue dye (exact type not given) was mixed into the active ingredient tank by Anglund and Ayers (2003) to visually monitor transport lag through a sprayer system, but the dye was not directly analyzed to determine actual concentrations. Dyes (Saturn Yellow, Brilliant Blue, Rhodamine B, and fluorescein) have also been used to quantify the concentration in applied solutions after contacting the plants or ground (de Cerqueira et al., 2012; Palladini et al., 2005). The suitability of a fluorescing dye (PTSA) as a tracer dye in agricultural sprayers was evaluated by Hoffmann et al. (2014). Rather than dyes, Vondricka and Lammers (2009a) used a decolorization reaction to investigate mixture homogeneity in nozzle direct injection systems. Finally, Luck et al. (2012) evaluated the effectiveness of Rhodamine WT mixed with glycerin for testing direct injection systems. Because all of these projects were focused on the determination of system characteristics in laboratory testing, the researchers were able to use expensive laboratory-grade equipment and selected chemicals with specific properties as stand-ins for actual chemical formulations, as the sensor did not have to operate during a standard spraying application in the field.

Most of the research involving concentration in direct injection has been focused on tests to identify application issues, such as the time lag for a rate change or mixing problems, or to evaluate different components or system configurations. These tests focused on quantifying the system to improve feedforward control of the concentration. Some authors specifically mentioned methods to improve feedforward control (Gillis et al., 2003), while most discussed design improvements for direct injection systems in general. Using feedforward control requires complete understanding of the relationship between system inputs and outputs (Ogata, 2004). In direct injection, this requires the use of high-precision metering components. In an example of this, Vondricka and Lammers (2009b) determined that a custom injection valve developed by the German Aerospace Center was necessary to produce accurate metering in direct injection. Feedback control would allow the use of relatively inaccurate, and therefore often less expensive, components and make the system relatively insensitive to disturbances (Ogata, 2004). The biggest drawback of using feedback control to improve this spraying system is that it requires a sensor capable of sensing chemical concentration to provide the feedback.

A concentration sensor would also have other potential uses outside of feedback for new direct injection systems. Because it would monitor the chemical application rate at the nozzle directly before spraying, it could also be used for creating precise nozzle-level "as-applied" maps when integrated with other precision agriculture technologies. Given the well-documented issues with lag and variations across the boom for rate changes with direct injection, this would help producers identify issues at the field level. The sensor could also be used to identify inadequate mixing of chemical and carrier or plugged or jammed components, as these would appear as concentration variations either over time or between nozzles. In tank mix systems, a concentration sensor at the nozzle could detect improperly mixed chemicals or when settling has occurred, as both would be registered as unexpected concentration variations.

The goal of this project was to develop and test a sensor that, when combined with production practices and calibrations, would enable determination of the chemical concentration at the nozzle level during standard in-field spraying operations. Based on the final sensor design developed, these production practices would include pre-mixing the dye and concentrated chemicals or purchasing only chemicals with guaranteed light transmission properties. Calibrations would be necessary for each dye and chemical mixture. Testing focused on determining if the sensor was accurate (i.e., properly detected chemical concentration) and consistent (i.e., measurements were repeatable). Thus, the objectives of this project were:

1. Develop a chemical concentration sensor that could be integrated with current spraying systems.

2. Determine the ability and accuracy of the sensor to detect concentration.

3. Determine the repeatability of concentration measurements.

\section{METHODS}

\section{SENSOR DESCRIPTION}

The sensor in this study is based on light transmission as detected by a simple photodiode and LED pair. A similar design is often used in turbidity sensors (Rasmussen et al., 2011) or suspended soil concentration sensors (Bigham, 2012) for environmental monitoring, although these sensors are often designed for detecting scattering or absorption rather than direct transmission. Similar structures have been used in sprayers for detecting mixture uniformity (Vondricka and Lammers, 2009a) or in pairs for nozzle flow rates (Dvorak and Bryant, 2015). A sensor body (fig. 1) houses the photodiode and LED pair. It was designed to be inserted between the nozzle body and flow control valve on a sprayer nozzle using the existing connection between these components. The flow control valve can be a check valve, a manual on/off valve, or a solenoid for PWM control. In this testing, a Wilger (Lexington, Tenn.) nozzle body was used, but similar fixtures could be created for other common nozzle bodies. In these nozzle bodies, the fluid flows up the outer path to the shutoff or solenoid valve and then down the central path to the nozzle. The LED and photodiode are located on either side of this central path to the nozzle, and they are separated by a distance of $5.9 \mathrm{~mm}$. This central flow path was machined from aluminum, and no special treatments were 


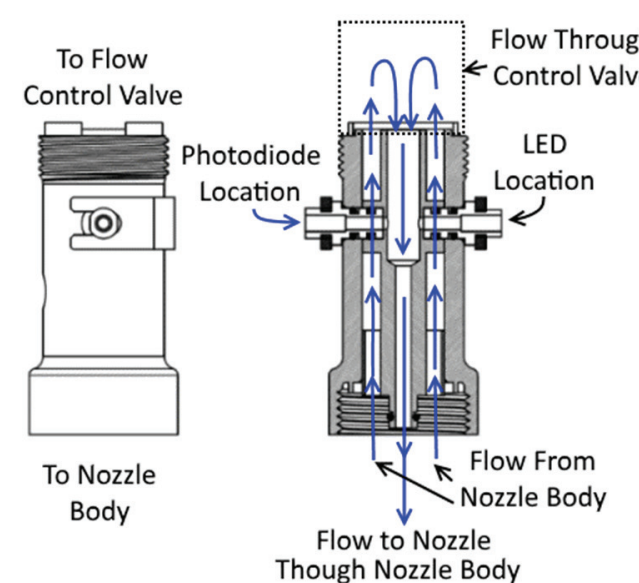

(a)

(b)

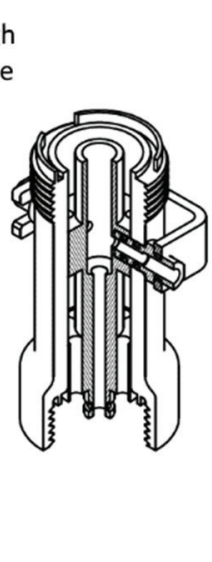

(c)

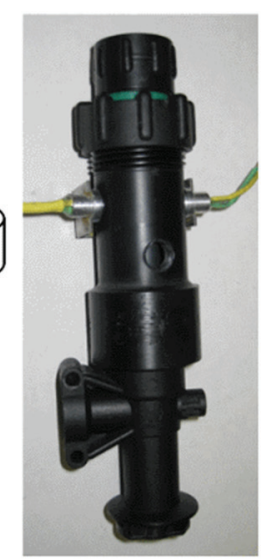

(d)

Figure 1. Sensor structure: (a) external view, (b) internal view, (c) 3/4 cutaway view, and (d) as installed on a Wilger nozzle body with shutoff valve in place.

added to adjust its reflectivity or color. The fluid flowing between the LED and photodiode on its way to the nozzle affects the intensity of light detected by the photodiode and thus its response.

\section{ELECTRONICS}

The intensity of the LED was adjusted using a circuit (fig. 2) based on an adjustable voltage regulator (LTC 1117, Linear Technologies, Milpitas, Cal.). The LED (WP710A10SRC/E, Kingbright Electronic Co., New Taipei City, Taiwan) had a peak wavelength of $660 \mathrm{~nm}$. The potentiometer (RV1) was set to $156 \Omega$ during testing, which produced $2.2 \mathrm{~V}$ between the voltage regulator and the LED current-limiting resistor (R5).

The photodiode signal conditioning circuit (fig. 3) consisted of a transimpedance amplifier to convert the current output of the photodiode (OP906, Optek, Carrollton, Tex.) into a voltage signal and a second stage to control gain. Both stages combined to create a lowpass filter with a cutoff frequency of $100 \mathrm{~Hz}$. Sudduth et al. (1995) also used a $100 \mathrm{~Hz}$ lowpass filter to remove effects from electrical noise in their concentration study using optical components. The potentiometer (RV2) adjusted the gain in the final stage of the signal conditioning circuit. It was set to $38.8 \mathrm{k} \Omega$ to provide a gain of $0.33 \mathrm{~V} \mu \mathrm{A}^{-1}$. With the illumination provided by the LED circuit and clear water flowing through the sensor, the photodiode provided $12 \mu \mathrm{A}$, which this circuit converted to just under $4 \mathrm{~V}$.

The voltage signal produced by the sensor's electronics was sampled by a multifunction DAQ (USB-6002, National Instruments, Austin, Tex.). It was configured to produce a reading every $16.7 \mathrm{~ms}$. This is $60 \mathrm{~Hz}$, and therefore slower

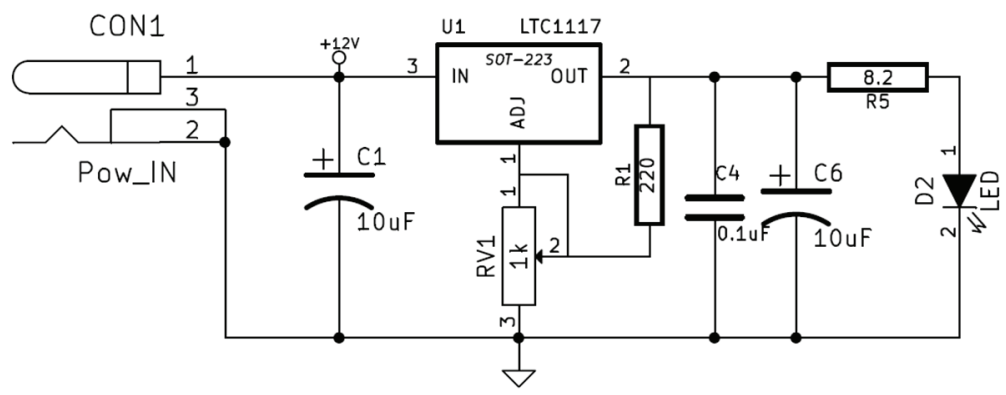

Figure 2. LED intensity control.

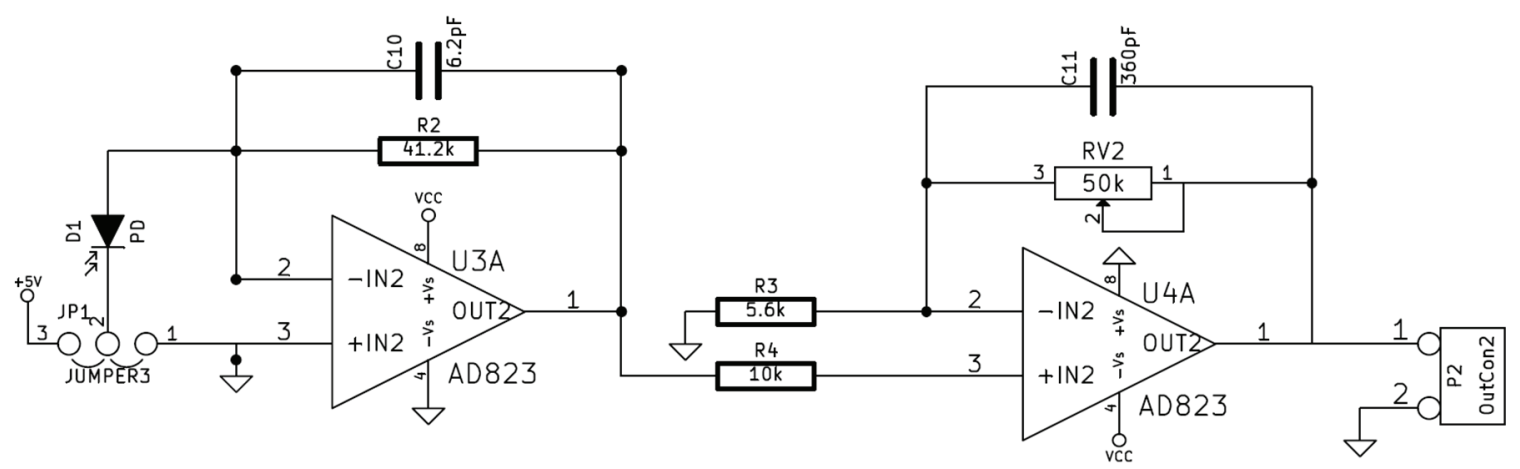

Figure 3. Photodiode signal conditioning circuit. 
than the cutoff frequency for the $100 \mathrm{~Hz}$ filter used in the signal conditioning circuit. In taking a measurement, the data acquisition system sampled at $30,000 \mathrm{~Hz}$ and averaged 500 samples to reduce any effects from noise in the data acquisition system. An average of 500 samples was also used by Sudduth et al. (1995) in their data acquisition system, although they were performing laboratory tests and used a $10 \mathrm{~s}$ total sample period. For this system, a sample period of $16.7 \mathrm{~ms}$ represents a reasonable approximation for sensor sampling time in actual operation. At a typical sprayer forward speed of $32 \mathrm{kph}$, this represents forward travel of $15 \mathrm{~cm}$. In its intended use, this sensor will be integrated with other machine electronics, and the design of the electrical interface components will undoubtedly be adjusted to better match the requirements of the on-machine electrical controllers. In this testing, averaging and lowpass filtering was used so that the effects of the components that would be changed in final implementation would not affect results.

\section{HERBICIDES AND DYES TESTED}

Both 2,4-D and glyphosate formulations were tested with the sensor. The glyphosate formulation used in this study was Mad Dog Plus (Loveland Products, Inc., Loveland, Colo.). The only active ingredient ( $41 \%$ by mass) in this formulation was glyphosate, $\mathrm{N}$-(phosphonomethyl)glycine, in the form of its isopropylamine salt. This was $480 \mathrm{~g} \mathrm{~L}^{-1}$ of active ingredient, which was the acid equivalent to $356 \mathrm{~g} \mathrm{~L}^{-1}$ of glyphosate. A glyphosate formulation was used in this study because it is commonly used in agricultural operations and is a clear, viscous, slightly yellow-colored solution (Loveland, 2013). In tests with simulated glyphosate, Luck et al. (2012) calculated that common application rates ranged from 10:1 to 107:1, which corresponds to just less than $1 \%$ up to $10 \%$ by volume.

A 2,4-D formulation was also used in this study as it represents another commonly used herbicide but with different optical properties. The formulation used was Amine 42,4-D weed killer (Loveland Products, Inc., Loveland, Colo.), and it is an amber to nearly black liquid (Loveland, 2012). The only active ingredient ( $46.5 \%$ by mass) was dimethylamine salt of 2,4-dichloro-phenoxyacetic acid. It was the acid equivalent to $38.6 \%$ by mass, or $448 \mathrm{~g} \mathrm{~L}^{-1}$ of $2,4-\mathrm{D}$. Based on the label, application rates varied from a low of $0.5 \%$ for broadleaf control in dormant strawberries to as high as $25 \%$ in forestry applications; however, food crop applications were limited to no more than $12 \%$ by volume. Because of the common application ranges for both herbicide formulations, the tested concentration range was selected as $0 \%$ to $12.5 \%$ by volume. These two pesticides represent two common chemicals used in agricultural spraying applications, and the specific formulations represent very different optical properties and were selected to provide different challenges to the sensor.

The dye used in these experiments was Standard Blue Dye (Bright Dyes, Miamisburg, Ohio), which is a formulation of Acid Blue 9. Acid Blue 9 has a CAS registry number of 3844-45-9 or 2650-18-2 depending on whether it is in disodium (most common) or diammonium form. It is also known as FD\&C Blue No. 1 or Brilliant Blue FCF (ACS, 2015). An excellent review of its toxicology, possible environmental effects, and suitability as a tracer dye is given by
Flury and Flühler (1994, 1995). Formulations of this same chemical are used in blue food coloring, and Standard Blue Dye is marketed for use in water tracing, leak detection, and decorative effects in outdoor bodies of water (Bright Dyes, 2015). Small amounts of the dye powder produce dramatic effects on light transmission, especially at $630 \mathrm{~nm}$, its wavelength of maximum absorption. This dye has been used by researchers in a wide variety of water infiltration studies (Bundt et al., 2001; Flury and Flühler, 1995; Motz et al., 2012; Vryzas et al., 2012).

\section{Test Procedure}

All tests performed with the sensor followed the same basic procedure. First, a cleaned and rinsed holding tank was filled with a certain amount of clean tap water from the Lexington, Kentucky, municipal water supply. The pump was started, and the initial reading was taken at this stage before adding dye or concentrated herbicide. When taking a measurement at a given concentration, 100 successive sensor readings were recorded. The concentration in the system of the substance being tested was then increased. The measurements at the new concentration were only recorded after waiting several minutes for the newly added dye or chemical to fully mix and any foaming caused by the added materials to subside. The concentration of chemical or dye in the holding tank was increased in increments, and successive measurements were made.

The experiments in this project were conducted in phases. In the first phase, the sensor was tested to determine its response to various concentrations of dye. This test with varying dye concentrations was repeated three times to determine the error that could be attributed to the experimental design that was shared among all dye and chemical tests. The second phase of the tests investigated the sensor's response to varying concentrations of the glyphosate formulation and the 2,4-D formulation. One test was performed with each formulation. The third phase of testing was performed to determine the nature of any interaction effects (if any) between the dye and the herbicide formulations. In this phase, the dye concentration was varied in a solution already containing high levels of each herbicide. Based on the results of the first three phases, a fourth test phase was conducted. In this final phase, a specific amount of dye was mixed with the concentrated herbicide to produce a specific output from the sensor for each concentration of the herbicide.

When testing with dye alone, the holding tank was initially filled with $20 \mathrm{~L}$ of water. The concentration of dye was varied from 0 to $50 \mathrm{mg} \mathrm{L}^{-1}$ in increments of $1.25 \mathrm{mg} \mathrm{L}^{-1}$ (table 1). Since an increment of $1.25 \mathrm{mg} \mathrm{L}^{-1}$ only corresponded to $25 \mathrm{mg}$ of dry powdered dye, the dye was premixed with water at a concentration of $25 \mathrm{~g} \mathrm{~L}^{-1}$. The dye concentration was increased by using a syringe to precisely add $1 \mathrm{~mL}$ of this concentrated liquid dye. Given the small amount of liquid added with the dye, the solution volume remained within $0.5 \%$ of the original volume during the test. The same procedure was used in the testing, in which dye was added to a solution already containing a high concentration of the chemical formulation. In this testing, the combined water and chemical formulation solution volume equaled $20 \mathrm{~L}$, so it represented the same starting volume as the dye-only testing. 
Table 1. Dye concentrations tested.

\begin{tabular}{|c|c|c|c|}
\hline $\begin{array}{l}\text { Solution } \\
\text { Volume } \\
\text { (L) }\end{array}$ & $\begin{array}{c}\text { Dye Mass } \\
\text { in Solution } \\
(\mathrm{mg})\end{array}$ & $\begin{array}{l}\text { Liquid Dye } \\
\text { in Solution } \\
(\mathrm{mL})\end{array}$ & $\begin{array}{c}\text { Dye } \\
\text { Concentration } \\
\left(\mathrm{mg} \mathrm{L}^{-1}\right)\end{array}$ \\
\hline 20.0 & 0 & 0 & 0.00 \\
\hline 20.0 & 25 & 1 & 1.25 \\
\hline 20.0 & 50 & 2 & 2.50 \\
\hline 20.0 & 75 & 3 & 3.75 \\
\hline 20.0 & 100 & 4 & 5.00 \\
\hline 20.0 & 125 & 5 & 6.25 \\
\hline 20.0 & 150 & 6 & 7.50 \\
\hline 20.0 & 175 & 7 & 8.75 \\
\hline 20.0 & 200 & 8 & 10.0 \\
\hline 20.0 & 225 & 9 & 11.2 \\
\hline 20.0 & 250 & 10 & 12.5 \\
\hline 20.0 & 275 & 11 & 13.7 \\
\hline 20.0 & 300 & 12 & 15.0 \\
\hline 20.0 & 325 & 13 & 16.2 \\
\hline 20.0 & 350 & 14 & 17.5 \\
\hline 20.0 & 375 & 15 & 18.7 \\
\hline 20.0 & 400 & 16 & 20.0 \\
\hline 20.0 & 425 & 17 & 21.2 \\
\hline 20.0 & 450 & 18 & 22.5 \\
\hline 20.0 & 475 & 19 & 23.7 \\
\hline 20.0 & 500 & 20 & 25.0 \\
\hline 20.0 & 525 & 21 & 26.2 \\
\hline 20.0 & 550 & 22 & 27.5 \\
\hline 20.0 & 575 & 23 & 28.7 \\
\hline 20.0 & 600 & 24 & 30.0 \\
\hline 20.0 & 625 & 25 & 31.2 \\
\hline 20.0 & 650 & 26 & 32.5 \\
\hline 20.0 & 675 & 27 & 33.7 \\
\hline 20.0 & 700 & 28 & 35.0 \\
\hline 20.0 & 725 & 29 & 36.2 \\
\hline 20.0 & 750 & 30 & 37.4 \\
\hline 20.0 & 775 & 31 & 38.7 \\
\hline 20.0 & 800 & 32 & 39.9 \\
\hline 20.0 & 825 & 33 & 41.2 \\
\hline 20.0 & 850 & 34 & 42.4 \\
\hline 20.0 & 875 & 35 & 43.7 \\
\hline 20.0 & 900 & 36 & 44.9 \\
\hline 20.0 & 925 & 37 & 46.2 \\
\hline 20.0 & 950 & 38 & 47.4 \\
\hline 20.0 & 975 & 39 & 48.7 \\
\hline 20.0 & 1000 & 40 & 50.0 \\
\hline
\end{tabular}

When testing with herbicide formulations, the herbicide represented a much larger share of the total volume. The tested volumetric concentrations varied from $0 \%$ to $12.5 \%$, and exact concentrations are listed in table 2 . The initial volume began at $17.5 \mathrm{~L}$ and ended with $20 \mathrm{~L}$ of solution. The active ingredient concentration (expressed using acid equivalent levels of the base chemical) varied from 0 to $56 \mathrm{~g} \mathrm{~L}^{-1}$ for 2,4-D and from 0 to $45 \mathrm{~g} \mathrm{~L}^{-1}$ for glyphosate.

The final test was with pre-mixed dye and 2,4-D. The tested concentrations of $2,4-\mathrm{D}$ matched the $0 \%$ to $12.5 \%$ by volume range ( 0 to $56 \mathrm{~g} \mathrm{~L}^{-1}$ active ingredient concentration) of the previous testing, and the dye concentrations varied from 0 to $10 \mathrm{mg} \mathrm{L}^{-1}$ (table 3).

\section{RESULTS AND DISCUSSION}

\section{Sensor Operational Parameters}

The average standard deviation among 100 samples taken at constant concentrations in all tests was only $0.69 \mathrm{mV}$ and remained consistent even as sensor output levels varied in response to the chemicals. This $0.69 \mathrm{mV}$ represents a range of chemical concentration values, as the sensor's transfer function was non-linear and varied depending on the chemical being monitored. For dye concentration, the $0.69 \mathrm{mV}$ standard deviation corresponds to a low of $1.0 \mu \mathrm{g} \mathrm{L}^{-1}$ to a high of $125 \mu \mathrm{g} \mathrm{L}^{-1}$. For the 2,4-D formulation, which was tested at concentrations of grams of active ingredient per liter rather than milligrams per liter, this same $0.69 \mathrm{mV}$ covers a range from 15.9 to $42.2 \mathrm{mg} \mathrm{L}^{-1}$. With the full-scale voltage at $4 \mathrm{~V}$, the $0.69 \mathrm{mV}$ represents a standard deviation of only $0.017 \%$ of full scale. The very small standard deviation between readings indicates that the sensor should provide consistent results when operating at the same concentration.

The time constant for the response of the sensor to a step change in input was $86 \mathrm{~ms}$. This was tested by suddenly switching from clear water to water with a dye concentration of $5 \mathrm{~g} \mathrm{~L}^{-1}$. The electrical components could change much faster, and the time constant for a step response generated by suddenly stopping all illumination was $7.2 \mathrm{~ms}$. Although the electrical components can register very rapid changes, the more complicated dynamics of fluid flow limit the overall response rate of the sensor.

\section{Dye CONCENTRATion}

The sensor design was highly responsive to concentrations of the Acid Blue 9 dye formulation (fig. 4). The relationship between dye concentration and the sensor is clearly a rational one. The rational model with the following equation fit the data from all three replications with an $\mathrm{R}^{2}$ value of 0.999:

$$
S O=\frac{31.7}{\left(C_{d y e}+8.28\right)}
$$

where $S O$ is sensor output $(\mathrm{V})$, and $C_{d y e}$ is concentration of dye ( $\left.\mathrm{mg} \mathrm{L}^{-1}\right)$.

The test procedure used for varying the dye concentration and the operation of the sensor was stable between different test runs. This is shown by the tight grouping of points for the different replications in figure 4 . As further verification of repeatability, the standard deviation was calculated for the three replications of each concentration. The maximum standard deviation in sensor output was $30 \mathrm{mV}(0.74 \%$ of the $4 \mathrm{~V}$ full scale) and occurred at $3.75 \mathrm{mg} \mathrm{L}^{-1}$. At this concentration level, small changes in concentration had a large effect on the output signal, so any small variations in dye concentration translated into large signal differences. The $30 \mathrm{mV}$ standard deviation represents only a $64.9 \mu \mathrm{g} \mathrm{L}^{-1}$ change in concentration at this level. The minimum standard deviation in sensor output was only $4 \mathrm{mV}(0.10 \%$ at $4 \mathrm{~V}$ full scale $)$ and occurred at the three highest concentration levels $\left(47.5,48.75\right.$, and $\left.50 \mathrm{mg} \mathrm{L}^{-1}\right)$. At these high concentrations, the $4 \mathrm{mV}$ standard deviation corresponded to a concentration of $429 \mu \mathrm{g} \mathrm{L}^{-1}$. Even with the very small $1.25 \mathrm{mg} \mathrm{L}^{-1}$ change between each dye concentration level tested, the difference in output signal between two consecutive concentration levels was always greater than the standard deviation between test runs at those concentration levels. This stability in the experimental process provides confidence in the methods and equipment. This was important for the tests with chemicals, where environmental and hazardous waste disposal concerns limited experiments to a single replication for each test situation. 
Table 2. Herbicide formulation concentrations tested.

\begin{tabular}{|c|c|c|c|c|c|c|}
\hline \multirow{2}{*}{$\begin{array}{l}\text { Solution } \\
\text { Volume } \\
\text { (L) }\end{array}$} & \multirow{2}{*}{$\begin{array}{c}\text { Formulation Volume } \\
\text { in Solution } \\
(\mathrm{L})\end{array}$} & \multirow{2}{*}{$\begin{array}{c}\text { Volumetric } \\
\text { Concentration } \\
(\%) \\
\end{array}$} & \multicolumn{2}{|c|}{$\begin{array}{l}\text { Active Ingredient }^{[\mathrm{a}]} \\
\text { Mass in Solution }(\mathrm{g})\end{array}$} & \multicolumn{2}{|c|}{$\begin{array}{c}\text { Active Ingredient }{ }^{[\mathrm{a}]} \\
\text { Concentration }\left(\mathrm{g} \mathrm{L}^{-1}\right)\end{array}$} \\
\hline & & & $2,4-\mathrm{D}$ & Glyphosate & $2,4-\mathrm{D}$ & Glyphosate \\
\hline 17.5 & 0 & 0.0 & 0 & 0 & 0 & 0 \\
\hline 17.6 & 0.05 & 0.3 & 22 & 18 & 1.3 & 1.0 \\
\hline 17.6 & 0.1 & 0.6 & 45 & 36 & 2.5 & 2.0 \\
\hline 17.7 & 0.15 & 0.8 & 67 & 53 & 3.8 & 3.0 \\
\hline 17.7 & 0.2 & 1.1 & 90 & 71 & 5.1 & 4.0 \\
\hline 17.8 & 0.3 & 1.7 & 134 & 107 & 7.6 & 6.0 \\
\hline 17.9 & 0.4 & 2.2 & 179 & 142 & 10 & 8.0 \\
\hline 18.0 & 0.5 & 2.8 & 224 & 178 & 12 & 10 \\
\hline 18.1 & 0.6 & 3.3 & 269 & 214 & 15 & 12 \\
\hline 18.2 & 0.7 & 3.8 & 314 & 249 & 17 & 14 \\
\hline 18.3 & 0.8 & 4.4 & 358 & 285 & 20 & 16 \\
\hline 18.4 & 0.9 & 4.9 & 403 & 320 & 22 & 17 \\
\hline 18.5 & 1 & 5.4 & 448 & 356 & 24 & 19 \\
\hline 18.6 & 1.1 & 5.9 & 493 & 392 & 26 & 21 \\
\hline 18.7 & 1.2 & 6.4 & 538 & 427 & 29 & 23 \\
\hline 18.8 & 1.3 & 6.9 & 582 & 463 & 31 & 25 \\
\hline 18.9 & 1.4 & 7.4 & 627 & 498 & 33 & 26 \\
\hline 19.0 & 1.5 & 7.9 & 672 & 534 & 35 & 28 \\
\hline 19.1 & 1.6 & 8.4 & 717 & 570 & 38 & 30 \\
\hline 19.2 & 1.7 & 8.9 & 762 & 605 & 40 & 32 \\
\hline 19.3 & 1.8 & 9.3 & 806 & 641 & 42 & 33 \\
\hline 19.4 & 1.9 & 9.8 & 851 & 676 & 44 & 35 \\
\hline 19.5 & 2 & 10.3 & 896 & 712 & 46 & 37 \\
\hline 19.6 & 2.1 & 10.7 & 941 & 748 & 48 & 38 \\
\hline 19.7 & 2.2 & 11.2 & 986 & 783 & 50 & 40 \\
\hline 19.8 & 2.3 & 11.6 & 1030 & 819 & 52 & 41 \\
\hline 19.9 & 2.4 & 12.1 & 1075 & 854 & 54 & 43 \\
\hline 20.0 & 2.5 & 12.5 & 1120 & 890 & 56 & 45 \\
\hline
\end{tabular}

Table 3. Mixed dye and 2,4-D formulation concentrations tested.

\begin{tabular}{|c|c|c|c|c|c|c|}
\hline \multirow{2}{*}{$\begin{array}{l}\text { Solution } \\
\text { Volume } \\
\text { (L) }\end{array}$} & \multirow{2}{*}{$\begin{array}{c}\text { Formulation Volume } \\
\text { in Solution } \\
(\mathrm{L})\end{array}$} & \multirow{2}{*}{$\begin{array}{c}\text { Volumetric } \\
\text { Concentration } \\
(\%) \\
\end{array}$} & \multicolumn{2}{|c|}{ Mass in Solution } & \multicolumn{2}{|c|}{ Concentration } \\
\hline & & & $\begin{array}{c}2,4-\mathrm{D}^{[\mathrm{a}]} \\
(\mathrm{g})\end{array}$ & $\begin{array}{l}\text { Dye } \\
(\mathrm{mg})\end{array}$ & $\begin{array}{c}2,4-\mathrm{D}^{[\mathrm{a}]} \\
\left(\mathrm{g} \mathrm{L}^{-1}\right)\end{array}$ & $\begin{array}{c}\text { Dye } \\
\left(\mathrm{mg} \mathrm{L}^{-1}\right)\end{array}$ \\
\hline 17.5 & 0 & 0.0 & 0 & 0 & 0 & 0.0 \\
\hline 17.6 & 0.05 & 0.3 & 22 & 4 & 1.3 & 0.2 \\
\hline 17.6 & 0.1 & 0.6 & 45 & 8 & 2.5 & 0.5 \\
\hline 17.7 & 0.15 & 0.8 & 67 & 12 & 3.8 & 0.7 \\
\hline 17.7 & 0.2 & 1.1 & 90 & 16 & 5.1 & 0.9 \\
\hline 17.8 & 0.3 & 1.7 & 134 & 24 & 7.6 & 1.3 \\
\hline 17.9 & 0.4 & 2.2 & 179 & 32 & 10 & 1.8 \\
\hline 18.0 & 0.5 & 2.8 & 224 & 40 & 12 & 2.2 \\
\hline 18.1 & 0.6 & 3.3 & 269 & 48 & 15 & 2.7 \\
\hline 18.2 & 0.7 & 3.8 & 314 & 56 & 17 & 3.1 \\
\hline 18.3 & 0.8 & 4.4 & 358 & 64 & 20 & 3.5 \\
\hline 18.4 & 0.9 & 4.9 & 403 & 72 & 22 & 3.9 \\
\hline 18.5 & 1 & 5.4 & 448 & 80 & 24 & 4.3 \\
\hline 18.6 & 1.1 & 5.9 & 493 & 88 & 26 & 4.7 \\
\hline 18.7 & 1.2 & 6.4 & 538 & 96 & 29 & 5.1 \\
\hline 18.8 & 1.3 & 6.9 & 582 & 104 & 31 & 5.5 \\
\hline 18.9 & 1.4 & 7.4 & 627 & 112 & 33 & 5.9 \\
\hline 19.0 & 1.5 & 7.9 & 672 & 120 & 35 & 6.3 \\
\hline 19.1 & 1.6 & 8.4 & 717 & 128 & 38 & 6.7 \\
\hline 19.2 & 1.7 & 8.9 & 762 & 136 & 40 & 7.1 \\
\hline 19.3 & 1.8 & 9.3 & 806 & 144 & 42 & 7.5 \\
\hline 19.4 & 1.9 & 9.8 & 851 & 152 & 44 & 7.8 \\
\hline 19.5 & 2 & 10.3 & 896 & 160 & 46 & 8.2 \\
\hline 19.6 & 2.1 & 10.7 & 941 & 168 & 48 & 8.6 \\
\hline 19.7 & 2.2 & 11.2 & 986 & 176 & 50 & 8.9 \\
\hline 19.8 & 2.3 & 11.6 & 1030 & 184 & 52 & 9.3 \\
\hline 19.9 & 2.4 & 12.1 & 1075 & 192 & 54 & 9.6 \\
\hline 20.0 & 2.5 & 12.5 & 1120 & 200 & 56 & 10.0 \\
\hline
\end{tabular}

[a] Acid equivalent of the active ingredient.

In these experiments with varying dye concentrations, increasing dye concentrations caused a monotonic decrease in the sensor's output. However, although monotonic, the actual change in sensor output was always less than $35 \mathrm{mV}$ for a step change of $1.25 \mathrm{mg} \mathrm{L}^{-1}$ when the dye concentration was greater than $20 \mathrm{mg} \mathrm{L}^{-1}$. Given the limited change in the output at concentration levels greater than $20 \mathrm{mg} \mathrm{L}^{-1}$, this sensor would operate most easily in applications that required de- 


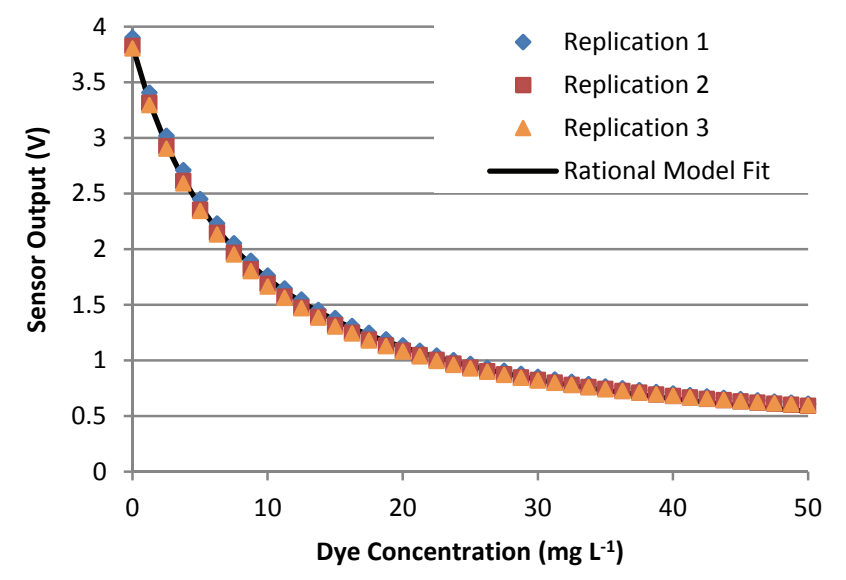

Figure 4. Sensor response to varying concentrations of dye.

tection of concentrations less than $20 \mathrm{mg} \mathrm{L}^{-1}$; otherwise, special care must be taken when designing the electronics for data acquisition to ensure they can correctly differentiate smaller voltage changes.

\section{HERBICIDE FORMULATION CONCENTRATION Glyphosate Formulation}

The tested glyphosate formulation, being a clear, slightly yellow liquid, had very little effect on the sensor's output (fig. 5). In figure 5, the concentration of the glyphosate formulation is shown by the concentration of the acid equivalent of its active ingredient, glyphosate. The minimum and maximum readings were within $3 \%$ of each other. Although there was a slight decreasing trend in sensor output at the very highest concentrations, it was not consistent across the concentration levels of interest for the glyphosate formulation's field use. Clearly, the sensor could not be used to determine chemical concentrations in spray solutions using this glyphosate formulation alone.

\section{2,4-D Formulation}

The 2,4-D formulation was a dark liquid, and its concentration had a definite impact on sensor output (fig. 6). In figure 6 , the concentration is expressed in concentration of its active ingredient. The relationship appears linear, and the

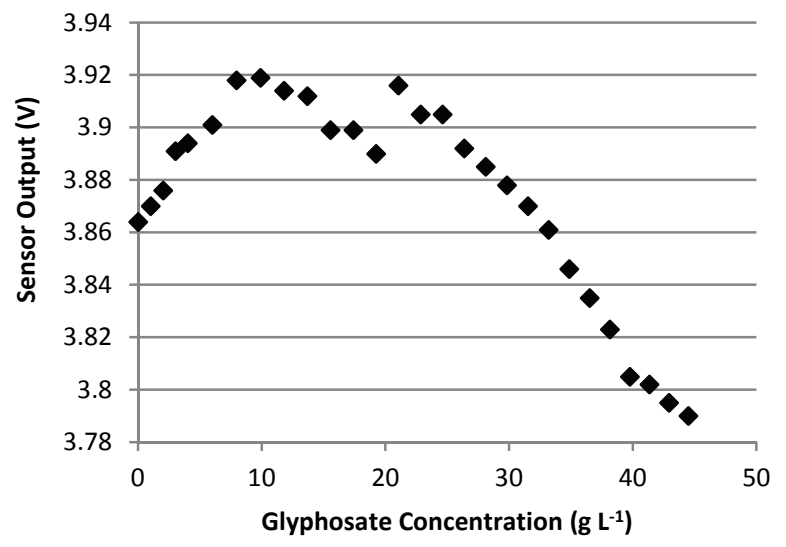

Figure 5. Effect on sensor output of glyphosate formulation concentration (expressed as concentration of its active ingredient).

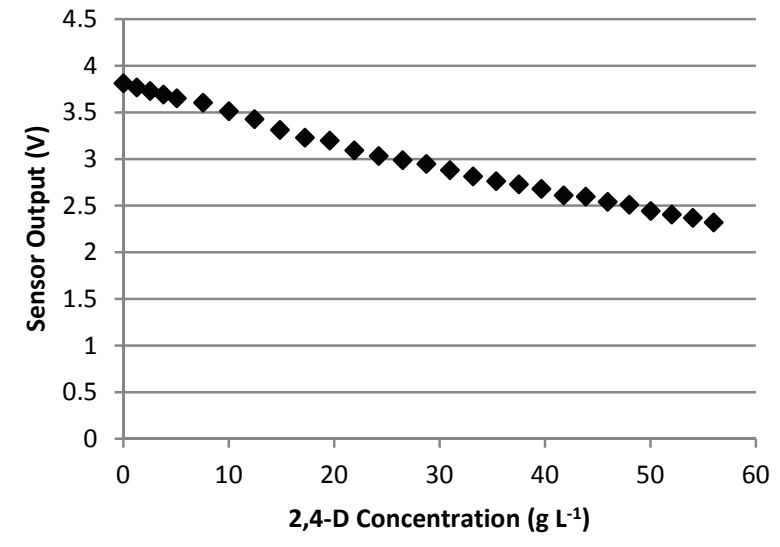

Figure 6. Effect on sensor output of 2,4-D formulation concentration (expressed as concentration of its active ingredient).

linear model with the following equation fit the data with an $\mathrm{R}^{2}$ value of 0.990 :

$$
S O=-0.0267 \times C_{2,4-\mathrm{D}}+3.75
$$

where $S O$ is sensor output $(\mathrm{V})$, and $C_{2,4-\mathrm{D}}$ is the concentration of 2,4-D $\left(\mathrm{g} \mathrm{L}^{-1}\right)$. Although the 2,4-D formulation reduced the signal from the sensor, its effect was much smaller than that of the dye. At the highest concentrations of the 2,4-D formulation, the sensor output only decreased to $2.4 \mathrm{~V}$, or $63 \%$ of full scale. This corresponds to a dye concentration of only $4.8 \mathrm{mg} \mathrm{L}^{-1}$. At these low concentration levels, the dye's effect also appeared linear. The rational relationship did not become apparent until higher concentrations. Therefore, it is very likely that at sufficiently high concentrations, the 2,4-D formulation would also demonstrate a rational relationship, so a rational model was also used to describe the effect of 2,4-D formulation concentration. The rational model with the following equation fit the data with an $\mathrm{R}^{2}$ value of 0.997 :

$$
S O=\frac{343}{\left(C_{2,4-\mathrm{D}}+88.9\right)}
$$

where $S O$ is sensor output $(\mathrm{V})$, and $C_{2,4-\mathrm{D}}$ is the concentration of 2,4-D $\left(\mathrm{g} \mathrm{L}^{-1}\right)$. It is hard to make comparison between fits with such high $\mathrm{R}^{2}$ values, but given that a rational model clearly applies with dye, this rational model was the one selected to represent the concentration of the 2,4-D formulation.

\section{HERBICIDE FORMULATION AND DYE INTERACTION Glyphosate Formulation with Dye}

Although the glyphosate formulation alone had very little effect on the sensor's output, it did affect how the sensor responded to dye (fig. 7). High concentrations of the glyphosate formulation caused a steeper drop in sensor output at low dye concentrations. However, the output in a glyphosate formulation solution was nearly identical to that in water at the highest dye concentrations tested $\left(50 \mathrm{mg} \mathrm{L}^{-1}\right)$. The rational model with the following equation fit the data with an $\mathrm{R}^{2}$ value of 0.990 : 


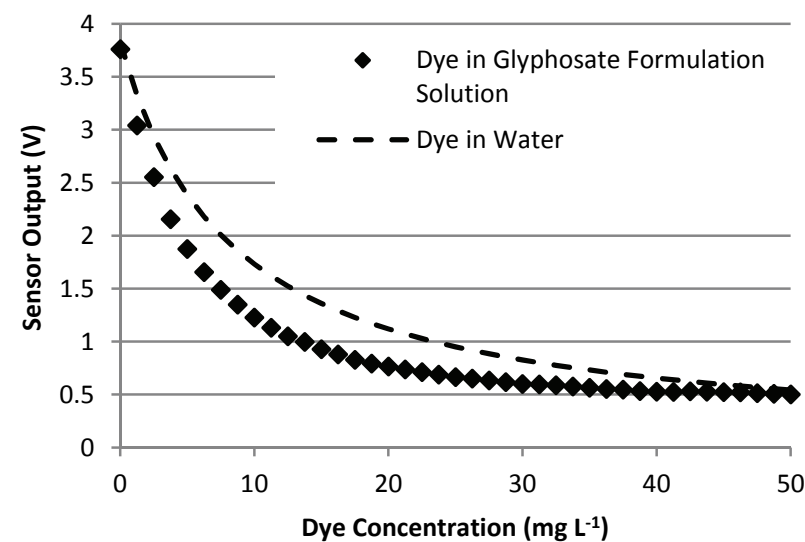

Figure 7. Effect on sensor output of dye concentration in a spray solution of glyphosate formulation $(\mathbf{1 2 . 5 \%}$ by volume) and water. Effect of dye concentration in water (dashed line) is shown for comparison.

$$
S O=\frac{20.1}{\left(C_{d y e}+5.44\right)}
$$

where $S O$ is sensor output (percent of full-scale output), and $C_{d y e}$ is concentration of dye $\left(\mathrm{mg} \mathrm{L}^{-1}\right)$.

Given that the glyphosate formulation alone did not produce a usable output from the sensor for determining concentration, an additive like the dye would have to be added to the concentrated glyphosate formulation to enable its detection. Unfortunately, the glyphosate formulation changes the effect of the dye, so the amount of dye to include in the glyphosate for a given effect is not as simple as looking at the dye's effect in water alone. Luck et al. (2012) also noted an effect on their Rhodamine WT dye when used with glycerin (as a stand-in for glyphosate), so it is not unusual that glyphosate itself would alter the light transmission properties with this dye as well. Determining the exact nature and root cause of this interaction effect is beyond the scope of this project. Some work, such as that by Luck et al. (2012), points to viscosity as a potential source, but these chemicals are complex, and their interactions need to be studied in other work. Because of these complex effects that determine fluid transparency, this work was conducted with actual herbicides rather than substitutes.

\section{2,4-D Formulation with Dye}

The effect of varying dye concentration in a high concentration of 2,4-D again followed a rational relationship (fig. 8), and the rational model with the following equation fit the data with an $\mathrm{R}^{2}$ value of 0.986 :

$$
S O=\frac{18.5}{\left(C_{d y e}+7.96\right)}
$$

where $S O$ is sensor output (percent of full-scale output), and $C_{d y e}$ is concentration of dye $\left(\mathrm{mg} \mathrm{L}^{-1}\right)$.

Although a rational relationship can be derived for the dye variations in this spray solution, it is more important to consider how the two solutions interact. There are two intuitive ways in which these materials (dye and formulation) could be combined:

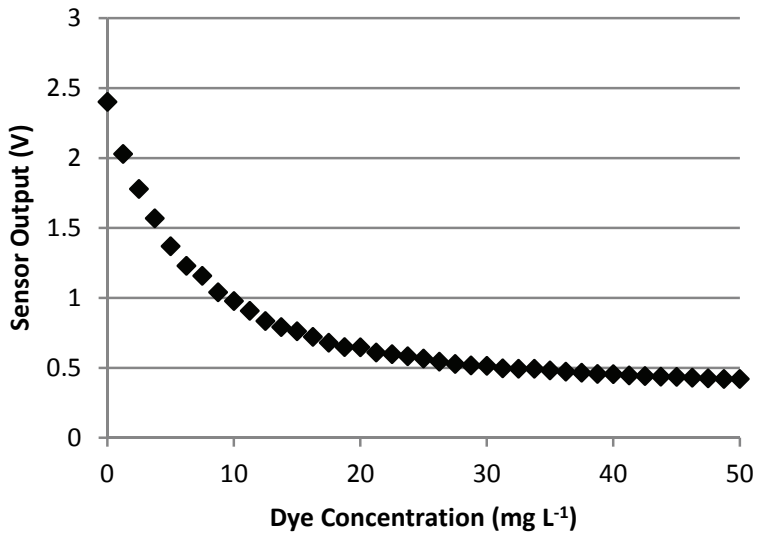

Figure 8. Effect on sensor output of dye concentration in a spray solution of 2,4-D formulation ( $12.5 \%$ by volume) and water.

1. Each material independently permits transmission of a certain percentage of light, and the overall effect is a multiplication of individual effects:

$$
S O=f\left(C_{\text {dye }}\right) \times g\left(C_{2,4-\mathrm{D}}\right)
$$

where $S O$ is sensor output, and $f\left(C_{d y e}\right)$ and $g\left(C_{2,4-\mathrm{D}}\right)$ are functions providing the expected sensor output (in percent of full scale) for given concentrations of dye and 2,4-D formulation, respectively.

2. All materials operate identically and can be treated as dyes of different concentrations:

$$
S O=f\left(C_{d y e}+f^{-1}\left[g\left(C_{2,4-\mathrm{D}}\right)\right]\right)
$$

where $f^{-1}$ is the inverse of the function $f\left(C_{d y e}\right)$.

These two approaches to combining the effects of dye are shown in figure 9. It is clear that treating the dye and chemical formulations independently follows the recorded data most closely ("independent prediction" dashed line). In this approach, it is assumed that the 2,4-D formulation at a $12.5 \%$ volumetric concentration only permits light transmission that corresponds to a sensor output of $2.4 \mathrm{~V}$. The effect of the dye is then considered independently, as if $2.4 \mathrm{~V}$ corre-

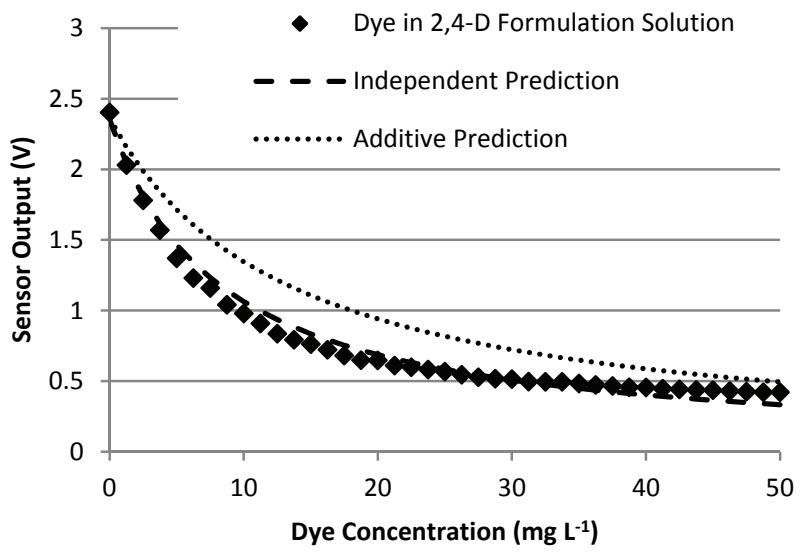

Figure 9. Approaches to combining effects of formulation and dye. 
sponded to the full level of sensor output.

The other method of combining the effects of the dye and chemical formulation treats the formulation as low-concentration dye. At $12.5 \%$ by volume concentration, the $2,4-\mathrm{D}$ formulation reduced sensor output to $2.4 \mathrm{~V}$. This is the same output as $4.8 \mathrm{mg} \mathrm{L}^{-1}$ of dye. To treat the formulation as dye, when adding dye to a $12.5 \%$ 2,4-D solution, the effect on sensor output is calculated as if an extra $4.8 \mathrm{mg} \mathrm{L}^{-1}$ of dye had been added. This is shown as the "additive prediction" in figure 9. It is clear that this approach does not match the data recorded.

\section{Premixed 2,4-D Formulation AND DYe}

This experiment most closely replicated the expected application of this technology. After determining that the effects of the dye and the herbicide formulation must be considered independently, the dye and herbicide were premixed and added together to the water. This test targeted a sensor output of $1 \mathrm{~V}$ when the concentration of the herbicide formulation was $12.5 \%$ by volume (corresponding to an active ingredient concentration of $56 \mathrm{~g} \mathrm{~L}^{-1}$ of 2,4-D).

The dye was added to the concentrated 2,4-D formulation to produce a solution with a dye concentration of $80 \mathrm{~g} \mathrm{~L}^{-1}$. Based on the combined equation for the effect of the 2,4-D formulation and dye, this mixture would generate an output of $1.08 \mathrm{~V}$ when it reached $12.5 \%$ volumetric concentration in the spray solution (active ingredient concentration of $56 \mathrm{~g}$ $\mathrm{L}^{-1} /$ dye concentration of $10 \mathrm{mg} \mathrm{L}^{-1}$ ). Using this concentration of dye in the premixed solution meant that, at the volumetric concentrations of interest ( $0 \%$ to $12.5 \%)$, the dye concentration in the final spray solution would vary between 0 and $10 \mathrm{mg} \mathrm{L}^{-1}$, which is where the variations in dye concentration have the strongest effect on sensor output (fig. 4). The outcome predicted by the equation for adding this premixed 2,4-D formulation and dye to water is shown in figure 10 along with the measured sensor response to the premixed solution. The equation produced a nearly perfect match with the recorded data.

With this formulation of 2,4-D, treating the effects of dye and formulation independently enabled a strong prediction of the outcome when dye was premixed with the formulation. It was possible to fine-tune the sensor's response to a

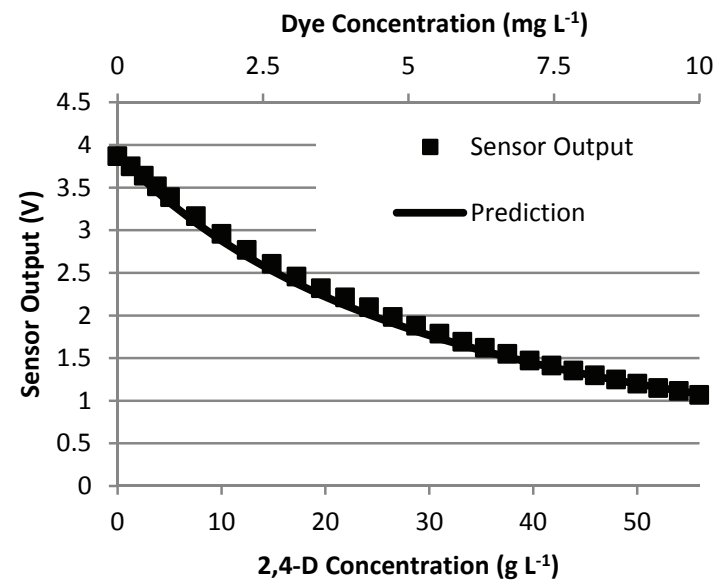

Figure 10. Effect on sensor output of premixed dye and 2,4-D. Prediction curve is shown for comparison. given concentration of chemical through the addition of a specific amount of dye to the concentrated chemical formulation. Although this method worked very well for this 2,4D formulation, testing will have to be extended to a much wider array of chemicals and formulations with different pigmentations. It is possible that the chemical structures of some chemicals could interact with light in the same manner as the dye, in which case it would be more appropriate to treat these formulations as low-concentration dyes. Use of the sensor for herbicide monitoring will require sensor calibration for each combination of herbicide and dye mixture, since the light transmittance properties of the tested mixtures were not quantified and the light transmittance properties of formulations and dyes can be arbitrarily changed by manufacturers.

Another issue arose during testing that might affect premixing dye and formulation off-farm and during manufacturing. In one test in which dye was being added to a glyphosate formulation solution, half of the test (to the $25 \mathrm{mg} \mathrm{L}^{-1}$ concentration) was performed on one day before stopping until the next morning. When testing resumed, the sensor output had increased by $92 \mathrm{mV}$. This was at a dye concentration of $25 \mathrm{mg} \mathrm{L}^{-1}$ and represented a large and noticeable jump in the data. It is apparent that some dye had settled out of the glyphosate formulation and water solution overnight. This dye is very stable in tap water and has remained in suspension at concentrations up to $5 \mathrm{~g} \mathrm{~L}^{-1}$ for over a year without settling. If mixing with formulations like the glyphosate formulation used in this study will cause the dye to settle at low concentrations, such as $25 \mathrm{mg} \mathrm{L}^{-1}$, care must be taken to ensure that it is well mixed before use, or incorrect concentration measurements could be made by the sensor. Expanded testing with multiple formulations could also consider the use of alternative dyes to determine those most suited to long-term suspension and light transmission stability.

\section{CONCLUSION}

Testing of a simple concentration sensor based on an LED and photodiode pair indicated that the sensor could be used to detect the concentration of certain herbicide formulations. The components in the sensor are robust and relatively low cost, which is a requirement if this sensor is to be used for concentration monitoring on every nozzle on a sprayer. The interface electronics do not require any special laboratorygrade components and would also be suitable for integration with sprayer electronics. The sensor provided a monotonic response to the concentration of the dye and the 2,4-D formulation, which enabled creation of an equation to predict sensor output based on concentration. Mostly clear solutions, such as the tested glyphosate solution, do not produce changes in the sensor's output suitable for calculating concentration. For concentration detection of these formulations, dye must be added. As illustrated by the tests with the premixed dye and chemical formulation, premixing can be used to produce a desired output for a given concentration of chemical. This sensor structure and its electronics are very stable, as shown by the extremely low $0.69 \mathrm{mV}$ standard de- 
viation of samples taken at constant dye or chemical formulation concentration levels. The sensor was also consistent between tests. In the repeated tests with the dye, the standard deviation between tests was always less than the step in the sensor's output produced by the small $\left(1.25 \mathrm{mg} \mathrm{L}^{-1}\right)$ change in concentration.

It is quite clear that this sensor can detect the concentration of certain chemical formulations and dye, and that its output can be adjusted by properly mixing the dye and formulation. Unfortunately, each chemical formulation is unique, and each would need to be tested to establish either the dye mixing ratio or the sensor output equation for that formulation. In addition, while this testing considered one of the most opaque and one of the clearest commonly available liquid herbicides, there are many formulations, additives, and delivery forms for active ingredients. Another concern is that chemical manufacturers could arbitrarily change the light transmittance properties of their formulations and dyes, which would necessitate recalibration. The sensor requires that the optical properties of the solution vary with the concentration of the chemical of interest. While dyes can be added to cause mostly clear chemical formulations to generate a response, there could be issues if the main carrier solution has been rendered so opaque by additives that additional slight changes are undetectable. Further testing will need to be conducted to determine the sensor's ability to operate under all the different conditions created by these substances. However, this project clearly demonstrates that this simple design can be used to detect the concentration of certain chemicals in a spray solution.

\section{ACKNOWLEDGEMENTS}

This work was funded with the support of Case-New Holland. This work is supported by the USDA National Institute of Food and Agriculture (NIFA) Hatch Multistate project under 1001110 .

\section{REFERENCES}

ACS. (2015). Common Chemistry. Washington, DC: American Chemical Society. Retrieved from http://www.commonchemistry.org/

Anglund, E. A., \& Ayers, P. D. (2003). Field evaluation of response times for a variable-rate (pressure-based and injection) liquid chemical applicators. Appl. Eng. Agric., 19(3), 273-282. http://dx.doi.org/10.13031/2013.13659

Ayers, P. D., Rogowski, S. M., \& Kimble, B. L. (1990). An investigation of factors affecting sprayer control system performance. Appl. Eng. Agric., 6(6), 701-706. http://dx.doi.org/10.13031/2013.26451

Bigham, D. (2012). Calibration and testing of a wireless suspended sediment sensor. PhD diss. Manhatten, KS: Kansas State University.

Bode, L. E., \& Bretthauer, S. M. (2007). Agricultural chemical application technology: A remarkable past and an amazing future. Trans. ASABE, 51(2), 391-395. http://dx.doi.org/10.13031/2013.24378

Bright Dyes. (2015). Standard Blue technical data. Miamisburg, $\mathrm{OH}$ : Bright Dyes. Retrieved from http://www.brightdyes.com/technical/StdBlue.html

Bundt, M., Widmer, F., Pesaro, M., Zeyer, J., \& Blaser, P. (2001). Preferential flow paths: Biological "hot spots" in soils. Soil Biol.
Biochem., 33(6), 729-738. http://dx.doi.org/10.1016/S00380717(00)00218-2

Crowe, T. G., Downey, D., Giles, D. K., \& Slaughter, D. C. (2005). An electronic sensor to characterize transient response of nozzle injection for pesticide spraying. Trans. ASAE, 48(1), 73-82. http://dx.doi.org/10.13031/2013.17942

de Cerqueira, D. T. R., Raetano, C. G., do Amaral dal Pogetto, M. H. F., Prado, E. P., Christovam, R. S., Serra, M. E., \& Almeida Costa, S. I. (2012). Agricultural spray deposit quantification methods. Appl. Eng. Agric., 28(6), 825-831. http://dx.doi.org/10.13031/2013.42474

Dvorak, J. S., \& Bryant, L. E. (2015). An optical sprayer nozzle flow rate sensor. Trans. ASABE, 58(2), 251-259. http://dx.doi.org/10.13031/trans.58.10765

Flury, M., \& Flühler, H. (1994). Brilliant Blue FCF as a dye tracer for solute transport studies: A toxicological overview. $J$. Environ. Qual., 23(5), 1108-1112. http://dx.doi.org/10.2134/jeq1994.00472425002300050037x

Flury, M., \& Flühler, H. (1995). Tracer characteristics of Brilliant Blue FCF. SSSA J., 59(1), 22-27. http://dx.doi.org/10.2136/sssaj1995.03615995005900010003x

Gillis, K. P., Giles, D. K., Slaughter, D. C., \& Downey, D. (2003). Injection mixing system for boomless, target-activated herbicide spraying. Trans. ASAE, 46(4), 997-1008. http://dx.doi.org/10.13031/2013.13954

Hoffmann, W. C., Fritz, B. K., \& Ledebuhr, M. A. (2014). Evaluation of 1,3,6,8-pyrene tetra sulfonic acid tetra sodium salt (PTSA) as an agricultural spray tracer dye. Appl. Eng. Agric., 30(1), 25-28. http://dx.doi.org/10.13031/aea.30.10313

Liu, H., Zhu, H., Shen, Y., Chen, Y., \& Ozkan, H. E. (2014). Development of digital flow control system for multi-channel variable-rate sprayers. Trans. ASABE, 57(1), 273-281. http://dx.doi.org/10.13031/trans.57.10216

Loveland. (2012). Material safety data sheet: Amine 42,4-D weed killer. Loveland, Colo.: Loveland Products. Retrieved from http://www.agrian.com/pdfs/Amine_4_24D_Weed_Killer_MSDS4.pdf

Loveland. (2013). Material safety data sheet: Mad Dog Plus. Loveland, Colo.: Loveland Products. Retrieved from http://www.agrian.com/pdfs/Mad_Dog_Plus_MSDS4.pdf

Luck, J. D., Sharda, A., Pitla, S. K., Fulton, J. P., \& Shearer, S. A. (2011). A case study concerning the effects of controller response and turning movements on application rate uniformity with a self-propelled sprayer. Trans. ASABE, 54(2), 423-431. http://dx.doi.org/10.13031/2013.36445

Luck, J. D., Shearer, S. A., Luck, B. D., \& Payne, F. A. (2012). Technical note: Evaluation of a rhodamine WT dye/glycerin mixture as a tracer for testing direct injection systems for agricultural sprayers. Appl. Eng. Agric., 28(5), 643-646. http://dx.doi.org/10.13031/2013.42424

Mercaldi, H., Fujiwara, C., Penaloza, E., Oliveira, V., \& Cruvinel, P. (2015). An intelligent and customized electrical conductivity sensor to evaluate the response time of a direct injection system. In Proc. 6th Intl. Conf. on Sensor Device Technologies and Applications. Retrieved from

http://www.thinkmind.org/index.php?view=article\&articleid=se nsordevices 2015 1 $40 \quad 20107$

Motz, E., Cey, E., Ryan, M. C., \& Chu, A. (2012). Vadose zone microbial transport below at-grade distribution of wastewater effluent. Water Air Soil Pollut., 223(2), 771-785. http://dx.doi.org/10.1007/s11270-011-0901-y

Needham, D. L., Holtz, A. J., \& Giles, D. K. (2012). Actuator system for individual nozzle control of flow rate and spray droplet size. Trans. ASABE, 55(2), 379-386.

http://dx.doi.org/10.13031/2013.41376

Ogata, K. (2004). System dynamics (4th ed.). Upper Saddle River, 
NJ: Pearson Prentice Hall.

Palladini, L. A., Raetano, C. G., \& Velini, E. D. (2005). Choice of tracers for the evaluation of spray deposits. Scientia Agricola, 62(5), 440-445. http://dx.doi.org/10.1590/S010390162005000500005

Porter, W. M., Rascon, J., Shi, Y., Taylor, R. K., \& Weckler, P. (2013). Laboratory evaluation of a turn compensation control system for a ground sprayer. Appl. Eng. Agric., 29(5), 655-662. http://dx.doi.org/10.13031/aea.29.10075

Rasmussen, P. P., Gray, J. R., Glysson, G. D., \& Ziegler, A. C. (2011). Guidelines and procedures for computing time-series suspended-sediment concentrations and loads from in-stream turbidity-sensor and streamflow data. USGS Techniques and Methods 3-C4. Reston, VA: U.S. Geological Survey.

Sharda, A., Fulton, J. P., McDonald, T. P., Zech, W. C., Darr, M. J., $\&$ Brodbeck, C. J. (2010a). Real-time pressure and flow dynamics due to boom section and individual nozzle control on agricultural sprayers. Trans. ASABE, 53(5), 1363-1371. http://dx.doi.org/10.13031/2013.34891

Sharda, A., Luck, J. D., Fulton, J. P., Shearer, S. A., \& McDonald, T. P. (2010b). Nozzle uniformity for agricultural sprayers operating under field operation when using automatic section technology. ASABE Paper No. 1009386. St. Joseph, MI: ASABE. http://dx.doi.org/10.13031/2013.35728

Sudduth, K. A., Borgelt, S. C., \& Hou, J. (1995). Performance of a chemical injection sprayer system. Appl. Eng. Agric., 11(3), 343348. http://dx.doi.org/10.13031/2013.25747

Sumner, H. R., Rains, G. C., \& Sumner, H. R. (2000). String collectors to determine lag time of injection sprayers. Appl. Eng. Agric., 16(5), 471-476. http://dx.doi.org/10.13031/2013.5296
Tompkins, F. D., Howard, K. D., Mote, C. R., \& Freeland, R. S. (1990). Boom flow characteristics with direct chemical injection. Trans. ASAE, 33(3), 737-743. http://dx.doi.org/10.13031/2013.31394

Vondricka, J., \& Schulze Lammers, P. (2009a). Measurement of mixture homogeneity in direct injection systems. Trans. $A S A B E$, 52(1), 61-66. http://dx.doi.org/10.13031/2013.25941

Vondricka, J., \& Schulze Lammers, P. (2009b). Real-time controlled direct injection system for precision farming. Prec. Agric., 10(5), 421-430. http://dx.doi.org/10.1007/s11119-0089093-X

Vryzas, Z., Papadakis, E. N., \& Papadopoulou-Mourkidou, E. (2012). Leaching of $\mathrm{Br}^{-}$, metolachlor, alachlor, atrazine, deethylatrazine, and deisopropylatrazine in clayey vadoze zone: A field-scale experiment in northeast Greece. Water Res., 46(6), 1979-1989. http://dx.doi.org/10.1016/j.watres.2012.01.021

Womac, A. R., \& Bui, Q. D. (2002). Design and tests of a variableflow fan nozzle. Trans. ASAE, 45(2), 287-295. http://dx.doi.org/10.13031/2013.8519

Zhu, H., Fox, R. D., Ozkan, H. E., Brazee, R. D., \& Derksen, R. C. (1998a). Mixture uniformity in supply lines and spray patterns of a laboratory injection sprayer. Appl. Eng. Agric., 14(3), 223-230. http://dx.doi.org/10.13031/2013.19380

Zhu, H., Fox, R. D., Ozkan, H. E., Brazee, R. D., \& Derksen, R. C. (1998b). A system to determine lag time and mixture uniformity for inline injection sprayers. Appl. Eng. Agric., 14(2), 103-110. http://dx.doi.org/10.13031/2013.19369

Zhu, H., Fox, R. D., Ozkan, H. E., Brazee, R. D., \& Derksen, R. C. (1998c). Time delay for injection sprayers. Trans. ASAE, 41(3), 525-530. http://dx.doi.org/10.13031/2013.17208 